Review

\title{
Structure, Activity and Function of the NSD3 Protein Lysine Methyltransferase
}

\author{
Philipp Rathert
}

check for

updates

Citation: Rathert, P. Structure, Activity and Function of the NSD3 Protein Lysine Methyltransferase. Life 2021, 11, 726. https:/ / doi.org/ $10.3390 /$ life11080726

Academic Editor: Jean Cavarelli

Received: 23 June 2021

Accepted: 21 July 2021

Published: 21 July 2021

Publisher's Note: MDPI stays neutral with regard to jurisdictional claims in published maps and institutional affiliations.

Copyright: (C) 2021 by the author. Licensee MDPI, Basel, Switzerland. This article is an open access article distributed under the terms and conditions of the Creative Commons Attribution (CC BY) license (https:// creativecommons.org/licenses/by/ $4.0 /)$.
Department of Biochemistry, Institute of Biochemistry and Technical Biochemistry, University of Stuttgart, 70569 Stuttgart, Germany; philipp.rathert@ibtb.uni-stuttgart.de; Tel.: +49-711-685-64388

\begin{abstract}
NSD3 is one of six H3K36-specific lysine methyltransferases in metazoans, and the methylation of H3K36 is associated with active transcription. NSD3 is a member of the nuclear receptorbinding SET domain (NSD) family of histone methyltransferases together with NSD1 and NSD2, which generate mono- and dimethylated lysine on histone H3. NSD3 is mutated and hyperactive in some human cancers, but the biochemical mechanisms underlying such dysregulation are barely understood. In this review, the current knowledge of NSD3 is systematically reviewed. Finally, the molecular and functional characteristics of NSD3 in different tumor types according to the current research are summarized.
\end{abstract}

Keywords: NSD3; WHSC1L1; structure and function

\section{Introduction}

In eukaryotes, DNA is assembled into a higher order nucleoprotein structure called chromatin. Besides the condensation of the DNA, chromatin poses a variety of different functions centered around the regulation of transcription, replication, DNA repair and recombination. The main unit of chromatin is the nucleosome consisting of 147 base pairs (bp) of DNA, which is wrapped around the histone octamer comprising two molecules of each core histone: $\mathrm{H} 2 \mathrm{~A}, \mathrm{H} 2 \mathrm{~B}, \mathrm{H} 3$ and $\mathrm{H} 4$ [1]. The linker histone protein $\mathrm{H} 1$ is involved in packaging nucleosomes and proteins such as condensin, cohesin, CCCTC-binding factor (CTCF) or Yin Yang 1 (YY1) to organize the chromatin into higher order structures such as gene loops, topologically associated domains (TADs), chromosome territories, and chromosomes [2-4]. Chromatin adopts a highly condensed structure, called heterochromatin, where genes are less accessible and generally transcriptionally silent. In turn, decondensed chromatin, called euchromatin, is much more accessible and harbors the majority of actively transcribed genes [5].

In order to establish or maintain a cell-type-specific gene expression program, the chromatin structures need to be highly dynamic to allow access of transcription factors and other regulatory entities to the DNA at defined time points. These events are tightly regulated by post-translational modifications (PTMs) which are enriched at the unstructured and flexible N-terminal regions of the histone proteins. These histone tails protrude from the nucleosome core and are subject to a diverse array of PTMs, e.g., acetylation, phosphorylation, ubiquitination and methylation, often referred to as the "histone code" that extends the information potential of the genetic code [6-8]. The "histone code" hypothesis suggests that specific patterns of modifications function as a barcode and recruit distinct combinations of proteins or protein complexes to drive specific transcriptional programs $[9,10]$.

Histone lysine methylation is among the best characterized PTM of the histone code and is attached to the basic side chains of lysine by a diverse set of sequence-specific lysine methyltransferases [11]. Histone lysine methylation mediates either an activating or repressive effect on gene transcription, which depends on the site, degree of methylation, genomic location, and the status of other coexisting PTMs [11]. The methylation of H3K36 
is generally linked to the transcriptionally active state and introduced by six different methyltransferases, which can establish H3K36 methylation to various degrees [12]. The nuclear receptor-binding SET domain (NSD) family of histone methyltransferases is composed of three members of this family, namely NSD1, NSD2 /MMSET /WHSC1, and NSD3 / WHSC1L1 (referred to as NSD2 and NSD3 from here on) [13], which all generate mono and dimethylation of lysine 36 on histone $\mathrm{H} 3$ (H3K36me1/me2).

NSD3 was first characterized in 2001 as the third member of the NSD gene family $[14,15]$. Despite the physiologic importance of NSD family proteins, their mechanisms of action are only beginning to become elucidated. In the following review, the structural and functional features of NSD3 will be discussed in more detail with references to the other family members in case information is available.

\section{Structural Features}

The full-length (FL) members of the NSD family of histone methyltransferases are large multidomain proteins, which share most of the evolutionary conserved domains. They belong to the so-called SET domain-containing lysine-specific methyltransferases [16] and the domain involved in the catalytic activity is the SET domain, named after the $\mathrm{Su}(\mathrm{var}) 3-9$, Enhancer-of-zeste and Trithorax (SET) proteins identified in Drosophila [17]. The SET domain is flanked by the associated with SET (AWS) and post-SET domains.

Besides the SET domain FL-NSD family members contain two PWWP domains named after its central core Pro-Trp-Trp-Pro motif, a five plant homeo domains (PHD) and a CysHis-rich domain $(\mathrm{C} 5 \mathrm{HCH})$ domain (Figure 1). Crystal structures showed that the fifth PHD domain (PHD5) and the adjacent Cys-His-rich domain $(\mathrm{C} 5 \mathrm{HCH})$, located at the $\mathrm{C}$ terminus of NSD3, fold into a novel PHD-PHD-like module recognizing the unmodified H3K4 and trimethylated H3K9 by PHD5. This function is not conserved between members of the NSD family, with PHD5 of NSD2 showing stronger preference for unmethylated H3K9 (H3K9me0) than trimethylated H3K9 (H3K9me3), and the NSD1 PHD5-C5HCH showed no binding to histone peptides at all [18], but is in involved in binding to the transcription cofactor Nizp1 in NSD1 [19-21].

Not much information is available about the specific roles of the other domains of NSD3, and most functions can only be roughly implied from information published for NSD1 and 2. The first N-terminal PWWP domains of NSD1 and 2 were shown to bind to methylated H3K36 to stabilize NSD2, and probably NSD1, at chromatin, and the catalytic SET domain of NSD2 propagates this gene-activating mark to adjacent nucleosomes [22-27].

The PHD1-3 motifs of NSD2 were shown to be important for its H3K36me2 methylation activity. Specifically, the removal of PHD1 decreased H3K36me2 activity and PHD2 caused NSD2 localization into the cytoplasm, which resulted in a complete loss of activity [28]. More details are known for the PHD domains of NSD1. These were shown to mediate binding of NSD1 to methylated $\mathrm{H} 3 \mathrm{~K} 4$ and $\mathrm{K} 9$ with a preference for dimethylated lysines in vitro [21]. Only the PHD4, PHD5 and C4HCH domains show binding to both modifications, which is controversial as both methylation states are associated with opposite transcriptional states [29-31]. The binding of various states of H3K4 and H3K9 methylation would allow NSD1 to recognize genes in stages of transcriptional activation and repression. It was therefore hypothesized that the activities of NSD1 cofactors would ultimately lead to either the enforcement, or alternatively, to the reversal of repression mechanisms [21].

All three members of the NSD family of histone H3K36 methyltransferases share most of the common motifs except NSD2, which contains a so-called high mobility group (HMG) domain. The HMG domain of NSD2 was shown to interact with the DNA-binding domain of the androgen receptor (AR), thereby enhancing the nuclear translocation of both proteins [32]. Future studies are necessary to reveal whether the common corresponding domains of NSD3 have similar roles. 


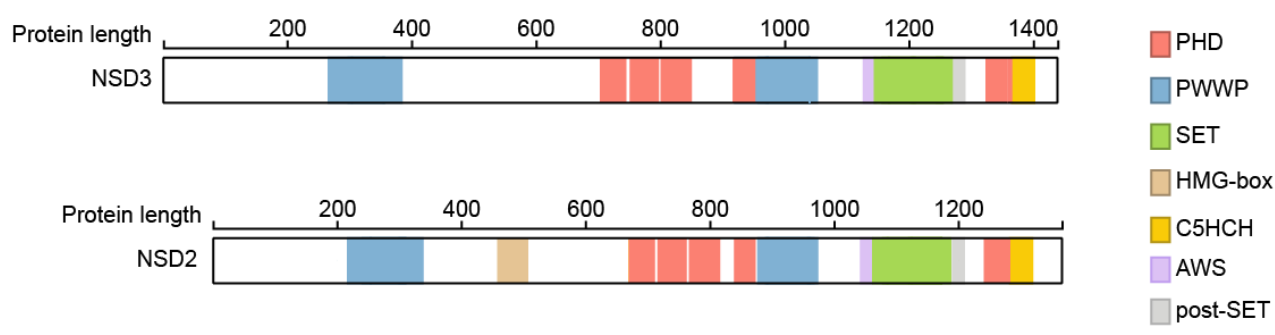

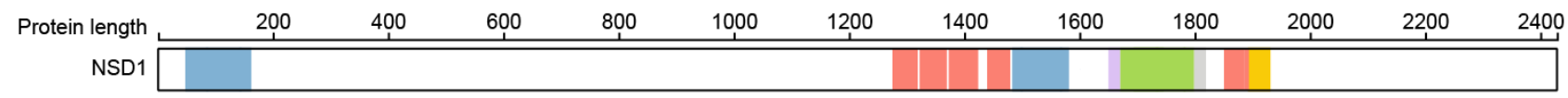

Figure 1. Structural relationship within the NSD family. The major domains of all three members of the NSD family of histone methyltransferases are highlighted. Numbers represent the number of amino acids in each full-length NSD protein. Proteins were extracted using ProteinPaint [33].

\section{NSD3 Structure}

The structure of the full-length NSD3 protein was never solved completely until now, due to its large protein size. An NSD3 construct containing amino acids 1054-1285, which spans the entire catalytic SET domain and additional residues on both sides without the reader domains, was crystallized in the presence of a histone $\mathrm{H} 4$ sequence flanking lysine 44 (H4K44), in which K44 was replaced by the unnatural amino acid norleucine (Nle) [34]. The catalytic part of NSD3 folds into a compact globular structure [34], which was confirmed later using cryo-electron microscopy (cryo-EM) studies on a larger version of NSD3 containing the C-terminal part of NSD3 starting from the first PHD domain (termed NSD3C) in complex with the nucleosome [35]. The histone peptide binds in a narrow groove and the lysine is occupying the substrate lysine channel. Interactions between the $\mathrm{H} 3$ tail and the SET domain are mainly mediated by hydrogen bonds, which tightly position the target lysine of $\mathrm{H} 3$ within the catalytic pocket. The hydrophobic side chain of the lysine points towards the methyl donor S-adenosylmethionine (SAM) through insertion into a hydrophobic pocket. [30]. The structures currently available for the NSD family show that a loop connecting the SET and post-SET domains can adopt multiple conformations, which are important for the regulation of the catalytic activity. This loop can extend over the $\mathrm{H} 3$ tail binding site of the SET domain, leading to autoinhibition [34,35] and significant reorganization of the autoinhibitory loop is observed in the structure of NSD3. In complex with the peptide, the autoinhibitory loop moves towards the C-terminus, which opens the substrate binding site for the peptide [34]. Similar to NSD3, the NSD1 and two post-SET domains are attached to the catalytic SET domain via an autoinhibitory loop region and inhibition is relieved upon nucleosome binding $[13,36]$.

The recent cryo-EM studies provided a more detailed view on the importance of the nucleosome-bound DNA in the activation of NSD3 [35]. NSD3 forms several contacts with the nucleosomal DNA and inserts between the histone octamer and the DNA near the linker region leading to an unwrapped segment of DNA [35] (Figure 2a). The interactions between NSD3 and the unwrapped DNA are required for the full activity of NSD3 and several basic residues from the long N-terminal loop bind to the unwrapped segment of DNA. This interaction of NSD3 to the DNA is strengthened by additional salt bridges between lysine and arginine residues of the SET and post-Set domain and the phosphate backbone [35]. Interactions within this region of DNA not only stabilize the binding between NSD3 and the nucleosome core particle (NCP), but also enable the positioning of the $\mathrm{H} 3$ tail in the substrate-binding groove of the SET domain (Figure 2b). The interaction of NSD3 with the DNA at several positions, which leads to the partial unwrapping of the DNA, is essential for the correct positioning of K36 in the active center and is a key factor that determines NSD3 substrate specificity. Additionally, NSD3 makes extensive intermolecular contacts with a short section of the $\mathrm{C}$ terminus of histone $\mathrm{H} 2 \mathrm{~A}$ as well as a long fragment of $\mathrm{H} 3$ that contains the first $\alpha$-helix and the $\mathrm{N}$-terminal tail. 

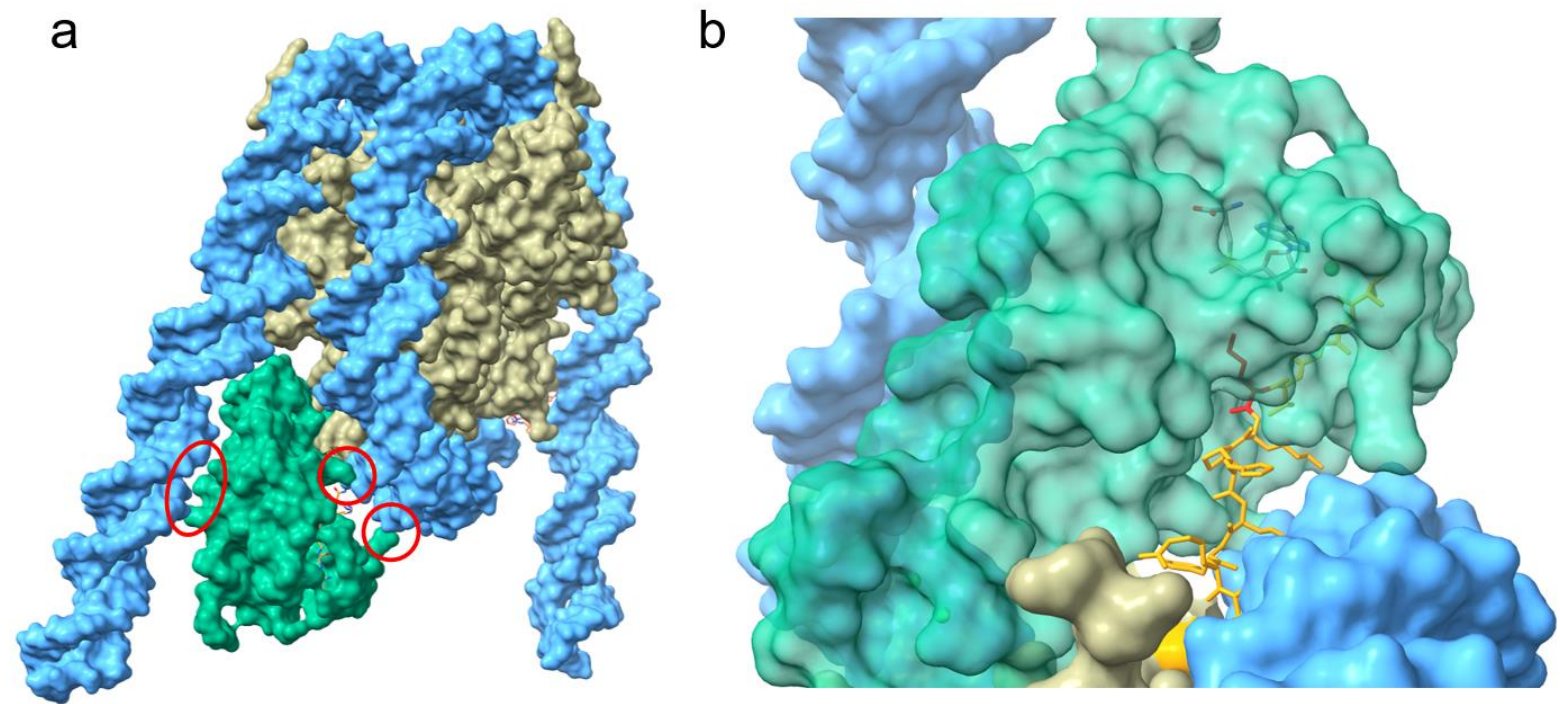

Figure 2. Surface representation of the structure of NSD3 bound to the nucleosome core particle (adopted from 7CRR PDB [35]). (a), NSD3 forms several contacts with the nucleosomal DNA (highlighted with red circles) and inserts between the DNA and the octamer. (b), Magnified view of the catalytic center of NSD3 showing the norleucine at position 36 is oriented in the catalytic center of NSD3. NSD3 is colored in green, the octamer in grey and the nucleosomal DNA in cyan. The bound $\mathrm{H} 3$ tail is shown in orange and the norleucine (inserted in the catalytic pocket of the SET domain) is depicted in red.

Furthermore, the AWS domain extends into the core histones and contacts the H2A $\mathrm{C}$-terminal fragment through hydrophobic and electrostatic interactions. These contacts result in an extended conformation of NSD3, rendering NSD3 catalytically active and contributing to the precise positioning of NSD3 to specifically bind H3K36. However, it is possible that the conformational states observed differ with the full-length protein when compared to truncated constructs, which could influence the regulation of the enzyme activity by the autoinhibitory loop.

Additionally, the C-terminal part of NSD3 the crystal structure of the PWWP1 domain of NSD3 (residues 247-398) was solved and revealed a classical PWWP domain fold, as described previously [37,38]. An $N$-terminal $\beta$-barrel of 5 antiparallel $\beta$-strands ( $\beta 1-\beta 5)$, with a short helix insertion between $\beta 4$ and $\beta 5$ is followed by $3 \alpha$ helices. The aromatic cage is formed by the aromatic amino acids Trp284, Tyr281, and Phe312, which are located at flexible loops connecting the different $\beta$-sheets. The aromatic cage could potentially accommodate an $\mathrm{H} 3$ peptide methylated at $\mathrm{K} 36$, indicated by the superimposition of the BRPF1-PWWP domain in complex with an H3K36me3 peptide [37,39].

\section{Biochemical Features}

The catalytic activity of the NSD family of histone H3K36 methyltransferases is restricted to a lower degree methylation of $\mathrm{H} 3 \mathrm{~K} 36$, and a specificity for mono and dimethylation is observed $[12,40]$. The substrate specificity of the NSD family of histone methyltransferases has long been debated and in vitro the catalytic domain (CTD) of NSD1, NSD2, and NSD3 were shown to recognize and methylate H3K4, H3K9, H3K27, H3K36, H3K79, and H4K20 peptides, with substantial differences in catalytic activities depending on the substrate [25]. NSD3 had previously been reported to specifically methylate H3K4 and H3K27 [41]. However, additional data with recombinant nucleosomes as substrate showed that the SET domains of all NSD family members specifically methylated K36 on histone H3. In contrast, when using recombinant histone octamers as substrate, the activity of NSD3 remained specific for H3 although with much lower activity, whereas the NSD2-SET domain mainly targeted $\mathrm{H} 4$ with very weak activity on $\mathrm{H} 3$ and the NSD1-SET domain methylated all components of the octamer, namely histone $\mathrm{H} 3, \mathrm{H} 2 \mathrm{~A} / \mathrm{H} 2 \mathrm{~B}$, and $\mathrm{H} 4$. Therefore, it was proposed that DNA acts as an allosteric effector of the NSD family proteins, 
such that H3K36 becomes the preferred target [42], which was recently confirmed through structural analysis [35].

Apart from the regulation of their enzymatic activity through binding of the nucleosome and the resulting clearance of the catalytic site from the autoregulatory loop, all members of the NSD family of histone methyltransferases are inhibited in their activity by different post translational modifications (PTMs) on histones. The ubiquitination of histone H2A at Lys119 [35,43] inhibits the activity of the whole NSD family of methyltransferases, which could be explained by the fact that they form extensive intermolecular contacts with the $\mathrm{C}$ terminus of histone H2A described for NSD3 [35]. Furthermore, the trimethylation of $\mathrm{H} 3$ at Lys4 also decreased the catalytic activity of NSD3, which correlates with the finding that the last PHD finger of NSD3 favors an unmodified Lys4 of H3 [18]. This suggests that binding of the unmodified $\mathrm{H} 3$ tail at lysine 4 contributes to some extent to the catalytic activity of NSD3. By contrast, the trimethylation of H3 at Lys27 did not alter the catalytic activity of NSD3 [35], which is intriguing because K27me3 rarely co-exists with K36me2 or K36me3 on the same histone. H3 polypeptide and PRC2 activity is greatly inhibited on nucleosomal substrates with preinstalled H3K36 methylation [44,45].

\section{Cellular Features}

NSD3 is ubiquitously expressed (Figure 3) and generates three major transcripts, a long (NSD3-long) isoform of 1437 amino acids, a short (NSD3-short) isoform containing 645 amino acids [14,15] and another short transcript called WHSC1-like 1 isoform 9 with methyltransferase activity to lysine (WHISTLE), which consists of 506 amino acids (Figure 4) [41].

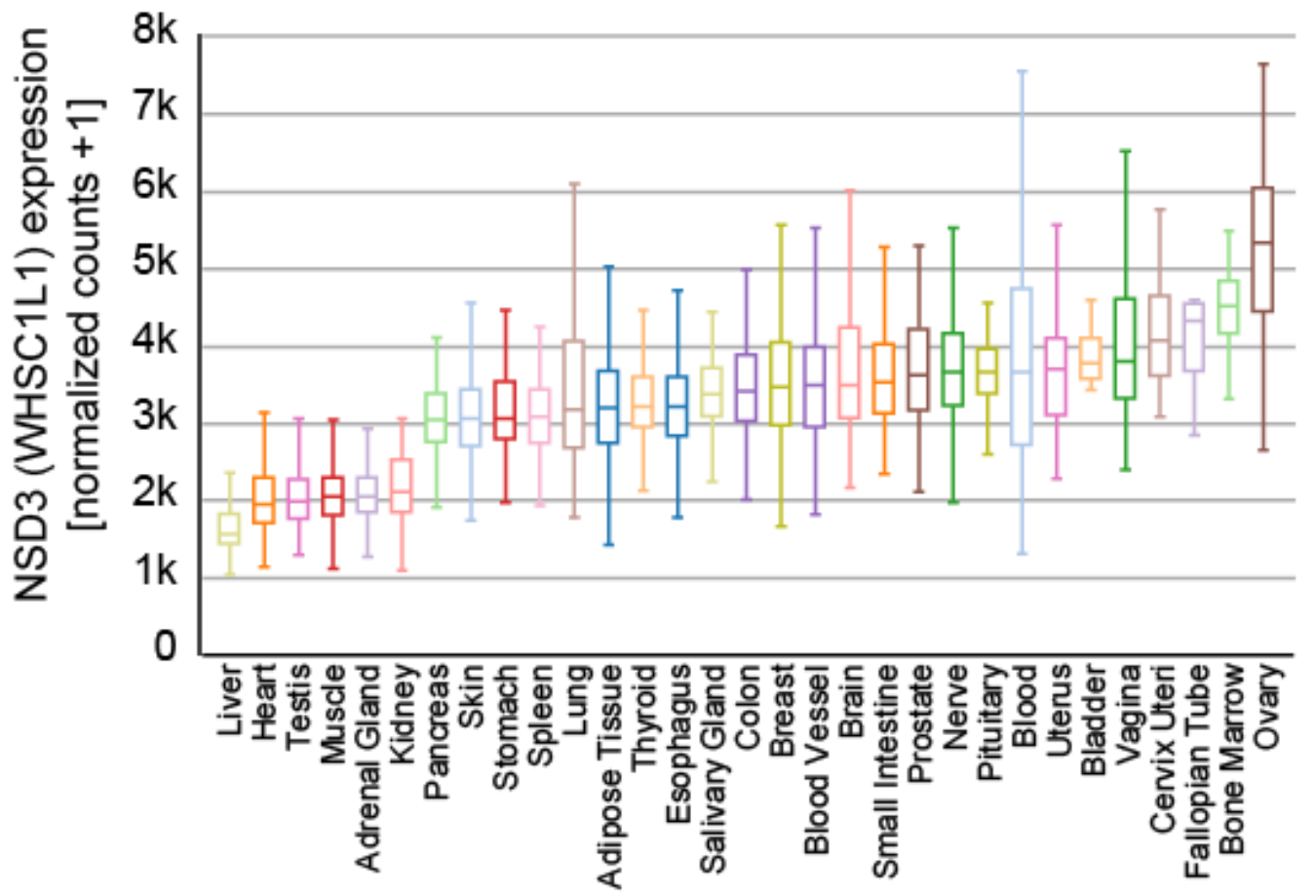

Figure 3. Expression of NSD3 across different human tissues. The data used for the analyses were obtained from the GTEx Portal (9783 samples). Visualization was generated with the UCSC Xena platform [46]. 


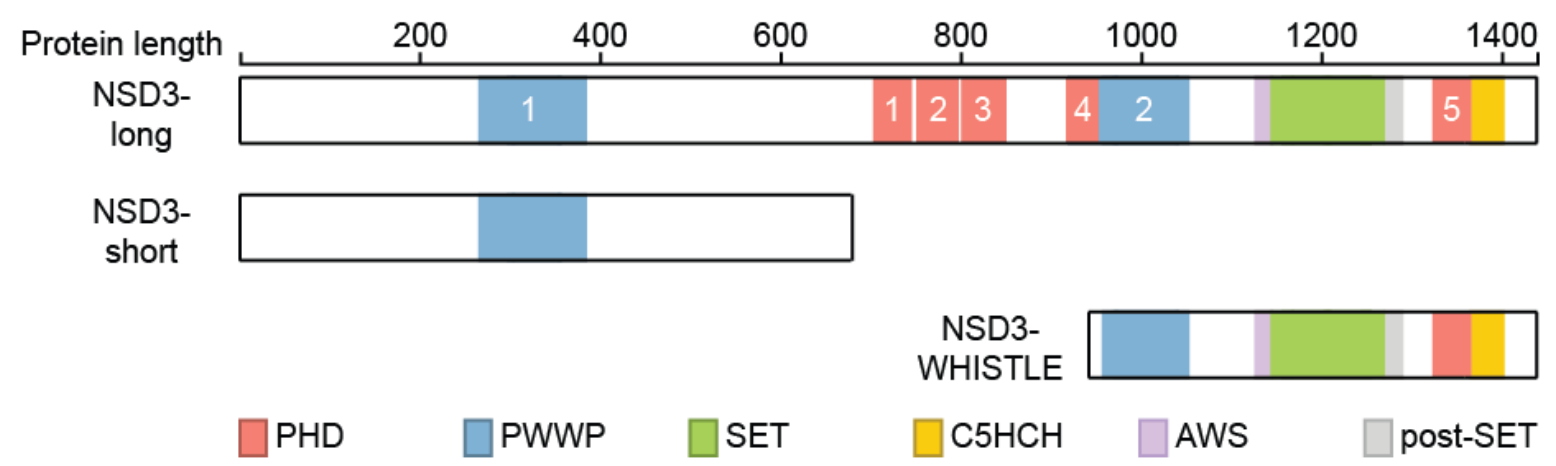

Figure 4. Isoforms of NSD3. Three isoforms of NSD3 are depicted and their domains were highlighted. Numbers of the different domains are indicated.

The NSD3-short protein lacks the catalytic SET domain and only contains the aminoterminal PWWP domain (Figure 2) [15] that binds to histone $\mathrm{H} 3$ when it is methylated on lysine 36 before [22]. NSD3-short was shown to interact with the bromodomain-containing protein 4 (BRD4) [47-49], which belongs to the bromodomain and extra-terminal domain (BET) protein family [50]. BRD4 plays an important role in controlling oncogene expression and genome stability and has sparked considerable interest as a drug target in multiple diseases in the past few years [51-53]. NSD3-short interacts with the extra terminal (ET) domain of BRD4 $[48,49]$, which functions as an adaptor protein that links BRD4 to the chromatin remodeler CHD8 to enable transcriptional programs [48].

Both the NSD3-long and NSD3-short transcripts are co-expressed in many tissues $[14,15]$, whereas WHISTLE was found to be mainly expressed in testis and in bone marrow mononuclear cells of AML and ALL patients [41]. In contrast to NSD3-long, WHISTLE only contains the second PWWP, SET, and post-SET domains (Figure 4) and was reported to facilitate transcriptional repression through its enzymatic activity and by recruiting HDACs [54], which is controversial to some extent, as all other reports connect NSD3 to transcriptional activation.

All NSD family proteins show methylation activity towards H3K36, which is restricted to mono and dimethylation $[12,40]$. Numerous studies in multiple systems support a role for H3K36 methylation in transcriptional activation [55,56]. While H3K36me3 exhibited characteristic enrichment within gene bodies, $\mathrm{H} 3 \mathrm{~K} 36 \mathrm{me} 2$ shows a very distinctive genomic occupancy pattern and displays a significant enrichment in promoters and intergenic regions in various cell types $[24,57,58]$ suggesting that H3K36me2 might play a role in enhancer regulation. Evidence for the function of $\mathrm{H} 3 \mathrm{~K} 36 \mathrm{me} 2$ in the regulation of enhancer accessibility was provided recently through the investigation of Nsd1-mediated H3K36me2 distribution [45,58]. Interestingly, the simultaneous presence of H3K36me2 and H3K27me2, which is regulated through the activity of the polycomb repressive complex 2 (PRC2) [59], strongly correlate in embryonic stem cells (ESCs), whereas H3K36me3 and H3K27me3 are anticorrelated [45]. A switch from di- to trimethylation at K36 induces an increase in H3K27me3 [45], which results in the downregulation of the enhancer activity. In line with this observation, NSD2 was shown to regulate epithelial plasticity by altering enhancer activity. H3K27ac peaks residing within intergenic H3K36me2 domains are lost when H3K36me2 levels decrease, providing another indication that H3K36me2 mediates its effects by modulating enhancer activity [60]. Due to its comparable substrate specificity and structural similarity, an analogous function could be conceived for NSD3 as well, but this needs to be investigated experimentally.

Furthermore, H3K36me2 is required for recruitment of DNMT3A and maintenance of DNA methylation at intergenic regions [58]. Genome-wide analysis showed that the binding and activity of DNMT3A co-localize with H3K36me2 at non-coding regions of euchromatin [58]. Accordingly, the PWWP domain of DNMT3A shows dual recognition of H3K36me2/3 in vitro with a higher binding affinity towards H3K36me2 [58,61]. However, ChIP-seq experiments investigating different lysine methylation states should be taken 
with great care. Many antibodies which are raised against a specific methylation state can show high cross-reactivity to other states at the same lysine residue [62]. Until now, it was unclear whether NSD3 contributes to the above-mentioned deposition of H3K36me2 at intergenic regions in other cell types where its expression is dominant over NSD1 and NSD2 or if the activity of NSD3 is restricted to other regulatory genomic elements.

Analogous to other known lysine methyltransferases [63], members of the NSD family were shown to methylate non-histone proteins. Apart from histone substrates, NSD3 recently was reported to methylate the epidermal growth factor receptor (EGFR), leading to enhanced activation [64], and NSD1 was shown to mono- and dimethylate p65, an NF- $\kappa B$ family transcription factor, at K218 and K221, which stimulates the expression of p65-dependent tumorigenic genes [65]. Furthermore, NSD1 was shown to methylate histone $\mathrm{H1}$ in a variant-specific manner [66].

\section{The Role of NSD3 in Cancer}

Knowledge about the function of NSD3 in individual diseases is sparse, and most of the information available is about its role in different tumors. NSD3 is located on chromosome 8p11.2, in a region which has been linked to various diseases and that is amplified in primary tumors and cell lines from breast carcinoma $[14,15]$. As well as NSD3, the 8p11.2 region contains a set of genes including TAM, FGFR1, and LETM2 [15,67].

Genomic alterations of NSD3 occur in multiple cancer types, implicating its cancerpromoting role $[12,68]$. In most cases, the fusion between the NUP98 and NSD3 genes was detected in patients with AML or myelodysplastic syndrome $[69,70]$, which promotes hematopoietic transformation in the same fashion as already shown for the NUP98-NSD1 fusion protein, due to the structural similarity between the two [71]. Besides the fusion to NUP98, NSD3 fusion has been observed with NUTM1 in primary pulmonary NUT carcinoma [72-74], which is known to typically harbor the BRD4/3-NUT fusion oncoprotein [75].

In line with the function of NSD3-short as an adaptor protein of BRD4 and CHD8 [48], MLL-AF9 rearranged acute myeloid leukemia (AML) were proven to be dependent on NSD3 $[48,51,76]$. This was confirmed by the development of a chemical probe for the PWWP1 domain of NSD3, which leads to the reduced proliferation of AML cell lines through the downregulation of MYC mRNA [37].

In addition, the 8p11.2 region is amplified in many cancers [67], leading to the increased expression of NSD3 (Figure 5), and reports have described NSD3 to be essential for tumor maintenance and the suppression of NSD3 expression leads to reduced cell proliferation in lung cancer [77-79], breast cancer [80,81], and osteosarcoma [82]. Furthermore, the 8p11.2 region is amplified in breast cancer $(B C)[14,80,81]$ and the overexpression of NSD3 is linked to overexpression of the estrogen receptor alpha $(E R \alpha)$ in breast cancer [80]. A similar scenario was described for colorectal cancer (CRC) [83]. Here, NSD3 was shown to be upregulated in CRC and the suppression of NSD3 expression resulted in a decrease in proliferation, migration, and EMT marker proteins such as E-cadherin and N-cadherin [83].

Thus far, only one non histone protein has been described, which is methylated by NSD3 [64]. The epidermal growth factor receptor (EGFR) was shown to be methylated by NSD3, leading to the enhanced activation of the associated ERK cascade without stimulation by EGF. In addition, nuclear EGFR was showed to enhance its interaction with proliferating-cell-nuclear-antigen (PCNA) resulted in enhanced proliferation in squamous cell carcinoma of the head and neck (SCCHN) [64].

Furthermore, over 260 mutations have been described within the NSD3 protein (Figure 6) and for most, the underlying change in protein function has not yet been described. Intermolecular contacts between NSD3 and nucleosomes are altered by several recurrent cancer-associated mutations. E1181K and T1232A substitution leads to enhanced enzymatic activity through preventing the autoinhibitory loop from blocking the active site, which improves the insertion of the target H3K36 into the catalytic pocket of NSD3 [35,79]. Both mutations were demonstrated to promote the proliferation of cancer cells and accel- 
erated growth of xenograft tumors [35]. There is no specific information available on the effect of the other mutations observed in NSD3.

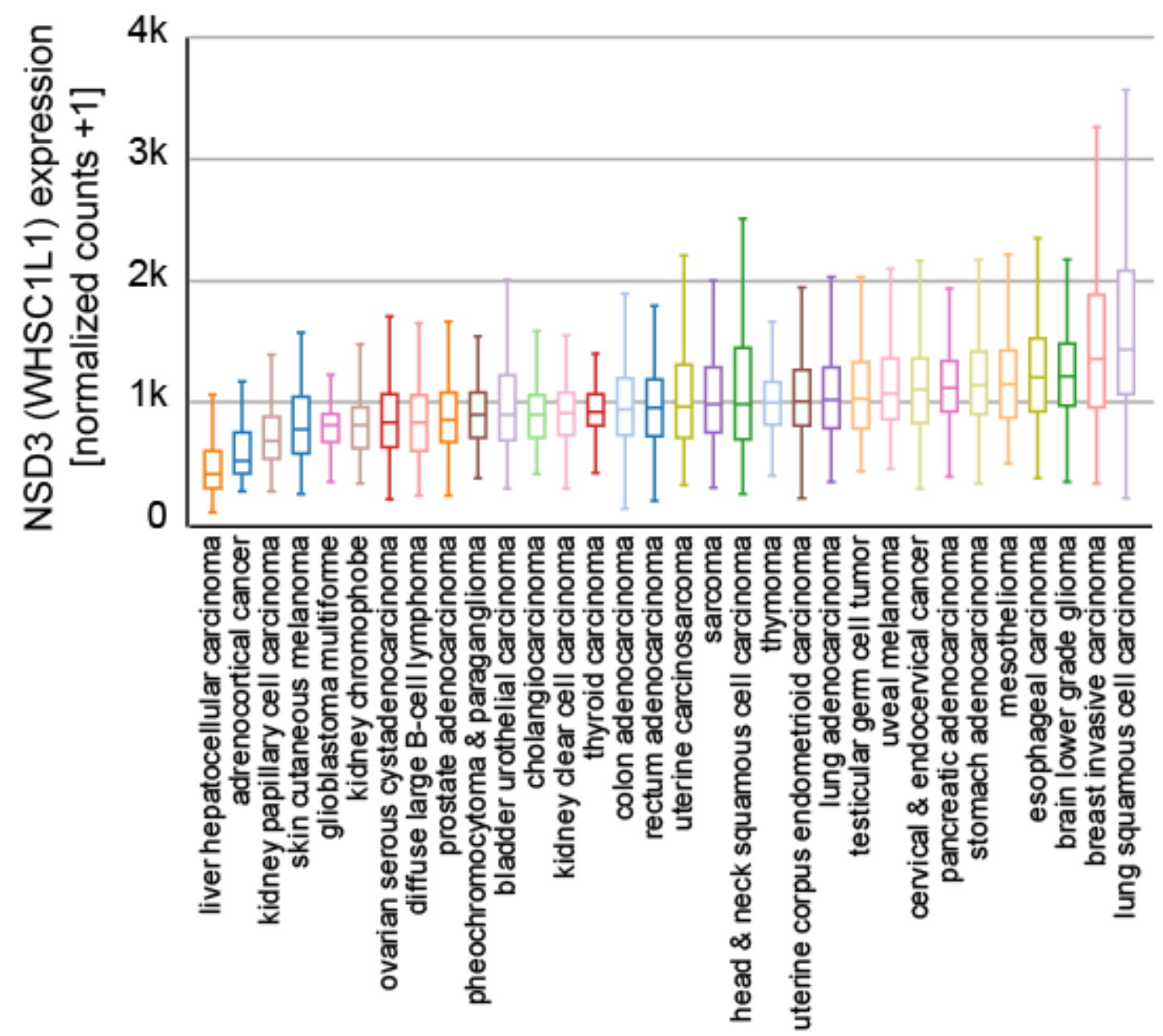

Figure 5. Expression of NSD3 in different indicated cancer subtypes. Samples from 9621 primary tumors of the TCGA Pan-Cancer set (https:/ / www.cancer.gov/tcga, accessed on 21 July 2021) are presented and visualized with the UCSC Xena platform [46].

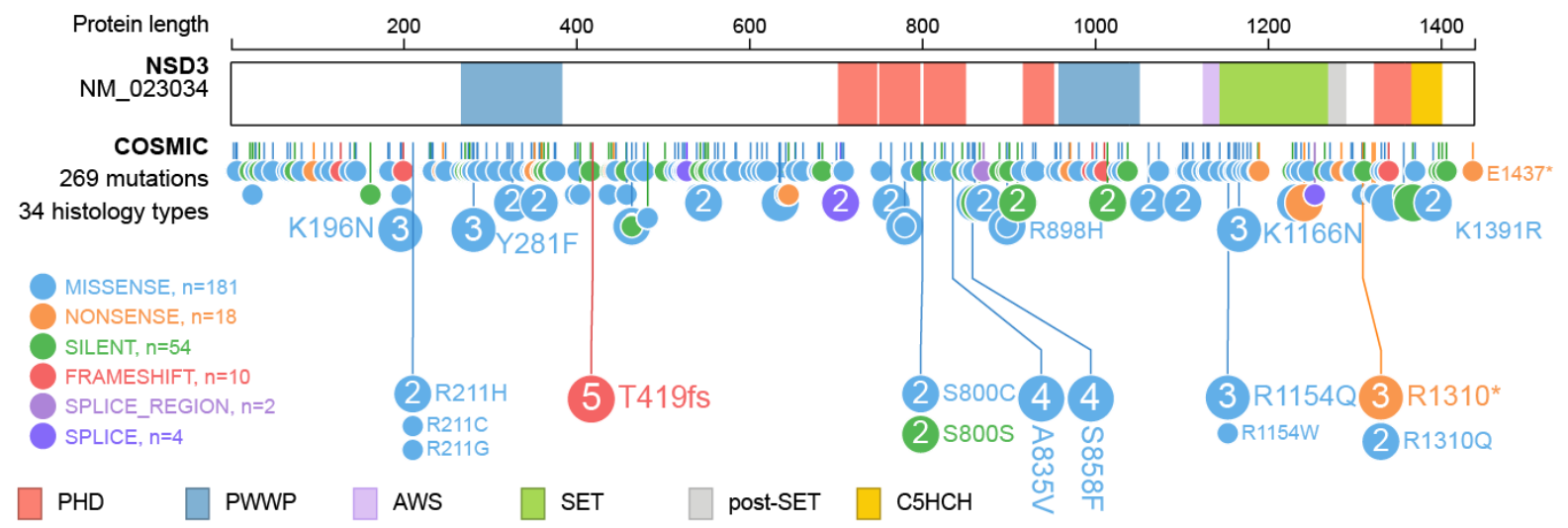

Figure 6. Mutations observed within NSD3. Visualization of NSD3 mutations listed in the Catalogue of Somatic Mutations In Cancer (COSMIC release 87) using ProteinPaint [33]. The major domains NSD3 are highlighted. Mutations are color coded as indicated. Numbers represent the number of amino acids. 
Besides mutations in NSD3 itself, so-called onco-histones harboring mutations of the lysine at position 36 [84-87], lead to alterations of the function of NSD3. Given the importance of H3K36me2 in maintaining active enhancers to regulate epithelial-to-mesenchymal identity, tumor differentiation, and metastasis $[45,60]$ it is inevitable that these onco-histones impose a strong negative impact on transcriptional maintenance. The incorporation of a lysine-to-methionine histone $\mathrm{H} 3$ mutant $(\mathrm{H} 3 \mathrm{~K} 36 \mathrm{M})$ led to a genome-wide reduction in H3K36me2 and H3K36me3 levels in different malignancies [60,86-89], which was attributed to a direct inhibitory effect of the H3.3K36M mutation on NSD2 and SET Domain Containing 2 (SETD2) [87]. Unfortunately, in these studies, the effect of the K36M mutation was not tested on NSD3 activity, but the comparable substrate specificities and structural similarities suggest a potential inhibitory effect on NSD3 as well.

Two recent publications shed more light on how altered NSD3 activity promotes tumor development and growth. These studies investigated the role of NSD3 in squamous cell lung cancer [79] and breast cancer [80]. Both showed that NSD3 acts as a factor that reprograms the chromatin landscape to promote oncogenic gene expression signatures. Elevated NSD3 expression [80] or hyperactivity [79] leads to an increase in H3K36me2 which inhibits the activity of the PRC2 complex [45]. This leads to the reexpression of developmental genes like MYC [79] or Notch3 [80], which promote stem cell like properties and in turn malignant transformation $[79,80]$.

\section{Outlook}

Despite the recent achievements in the structural and biochemical analyses of NSD3 in complex with the nucleosome, which provided a molecular basis for the nucleosomal preference and activation mechanism of NSD proteins, not much information is available on cellular functions of NSD3 itself. Nevertheless, the fact that the methylation of H3K36 plays such an important role in regulating enhancer activity $[45,60]$ and NSD3 is amplified in many cancers $[14,67,73,77,79,80]$, suggests that NSD3 must play an important role in many different cellular processes. Epigenetic-based therapies are emerging as effective and valuable approaches in cancer and targeting NSD3 may indeed present a valuable approach $[37,48,51,76]$. However, the existence of at least six histone methyltransferases, which are capable of methylating $\mathrm{H} 3 \mathrm{~K} 36$, complicate the efforts in understanding the effects of NSD3 in cells, and further work will be needed to clarify these roles.

Funding: This research received no external funding.

Institutional Review Board Statement: Not applicable.

Informed Consent Statement: Not applicable.

Data Availability Statement: Not applicable.

Conflicts of Interest: The authors declare no conflict of interest.

\section{References}

1. Kornberg, R.D.; Lorch, Y.L. Twenty-Five Years of the Nucleosome, Fundamental Particle of the Eukaryote Chromosome. Cell 1999, 98, 285-294. [CrossRef]

2. Davis, L.; Onn, I.; Elliott, E. The emerging roles for the chromatin structure regulators CTCF and cohesin in neurodevelopment and behavior. Cell. Mol. Life Sci. 2018, 75, 1205-1214. [CrossRef]

3. Dekker, J.; Mirny, L. The 3D Genome as Moderator of Chromosomal Communication. Cell 2016, 164, 1110-1121. [CrossRef]

4. Atchison, M.L. Function of YY1 in Long-Distance DNA Interactions. Front. Immunol. 2014, 5, 45. [CrossRef] [PubMed]

5. Hildebrand, E.M.; Dekker, J. Mechanisms and Functions of Chromosome Compartmentalization. Trends Biochem. Sci. 2020, 45, 385-396. [CrossRef] [PubMed]

6. Turner, B.M. Histone acetylation and an epigenetic code. Bioessays 2000, 22, 836-845. [CrossRef]

7. Strahl, B.D.; Allis, C.D. The language of covalent histone modifications. Nature 2000, 403, 41-45. [CrossRef] [PubMed]

8. Fischle, W.; Wang, Y.M.; Allis, C.D. Histone and chromatin cross-talk. Curr. Opin. Cell Biol. 2003, 15, 172-183. [CrossRef]

9. Jenuwein, T.; Allis, C.D. Translating the Histone Code. Science 2001, 293, 1074-1080. [CrossRef] [PubMed]

10. Cosgrove, M.S.; Wolberger, C. How does the histone code work? Biochem. Cell Biol. 2005, 83, 468-476. [CrossRef] 
11. Greer, E.L.; Shi, Y. Histone methylation: A dynamic mark in health, disease and inheritance. Nat. Rev. Genet. 2012, 13, 343-357. [CrossRef]

12. Li, J.; Ahn, J.H.; Wang, G.G. Understanding histone H3 lysine 36 methylation and its deregulation in disease. Cell. Mol. Life Sci. 2019, 76, 2899-2916. [CrossRef]

13. Bennett, R.L.; Swaroop, A.; Troche, C.; Licht, J.D. The Role of Nuclear Receptor-Binding SET Domain Family Histone Lysine Methyltransferases in Cancer. Cold Spring Harb. Perspect. Med. 2017, 7, a026708. [CrossRef]

14. Angrand, P.-O.; Apiou, F.; Stewart, A.F.; Dutrillaux, B.; Losson, R.; Chambon, P. NSD3, a New SET Domain-Containing Gene, Maps to 8p12 and Is Amplified in Human Breast Cancer Cell Lines. Genomics 2001, 74, 79-88. [CrossRef]

15. Stec, I.; Van Ommen, G.J.B.; den Dunnen, J.T. WHSC1L1, on Human Chromosome 8p11.2, Closely Resembles WHSC1 and Maps to a Duplicated Region Shared with 4p16.3. Genomics 2001, 76, 5-8. [CrossRef] [PubMed]

16. Wood, A.; Shilatifard, A. Posttranslational Modifications of Histones by Methylation. Adv. Protein Chem. 2004, 67, 201-222. [CrossRef]

17. Alvarez-Venegas, R.; Avramova, Z. SET-domain proteins of the Su(var)3-9, E(z) and Trithorax families. Gene 2002, 285 , 25-37. [CrossRef]

18. He, C.; Li, F.D.; Zhang, J.H.; Wu, J.H.; Shi, Y.Y. The Methyltransferase NSD3 Has Chromatin-binding Motifs, PHD5-C5HCH, That Are Distinct from Other NSD (Nuclear Receptor SET Domain) Family Members in Their Histone H3 Recognition. J. Biol. Chem. 2013, 288, 4692-4703. [CrossRef]

19. Berardi, A.; Quilici, G.; Spiliotopoulos, D.; Corral-Rodriguez, M.A.; Martin-Garcia, F.; Degano, M.; Tonon, G.; Ghitti, M.; Musco, G. Structural basis for PHD(V)C5HCH(NSD1)-C2HR(Nizp1) interaction: Implications for Sotos syndrome. Nucleic Acids Res. 2016, 44, 3448-3463. [CrossRef]

20. Nielsen, A.L.; Jorgensen, P.; Lerouge, T.; Cerviño, M.; Chambon, P.; Losson, R. Nizp1, a Novel Multitype Zinc Finger Protein That Interacts with the NSD1 Histone Lysine Methyltransferase through a Unique C2HR Motif. Mol. Cell. Biol. 2004, 24, 5184-5196. [CrossRef]

21. Pasillas, M.P.; Shah, M.; Kamps, M.P. NSD1 PHD domains bind methylated H3K4 and H3K9 using interactions disrupted by point mutations in human sotos syndrome. Hum. Mutat. 2011, 32, 292-298. [CrossRef]

22. Vermeulen, M.; Eberl, H.C.; Matarese, F.; Marks, H.; Denissov, S.; Butter, F.; Lee, K.K.; Olsen, J.V.; Hyman, A.A.; Stunnenberg, H.G.; et al. Quantitative Interaction Proteomics and Genome-wide Profiling of Epigenetic Histone Marks and Their Readers. Cell 2010, 142, 967-980. [CrossRef]

23. Wu, H.; Zeng, H.; Lam, R.; Tempel, W.; Amaya, M.F.; Xu, C.; Dombrovski, L.; Qiu, W.; Wang, Y.; Min, J. Structural and Histone Binding Ability Characterizations of Human PWWP Domains. PLoS ONE 2011, 6, e18919. [CrossRef]

24. Kuo, A.J.; Cheung, P.; Chen, K.F.; Zee, B.M.; Kioi, M.; Lauring, J.; Xi, Y.X.; Park, B.H.; Shi, X.B.; Garcia, B.A.; et al. NSD2 Links Dimethylation of Histone H3 at Lysine 36 to Oncogenic Programming. Mol. Cell 2011, 44, 609-620. [CrossRef]

25. Morishita, M.; Mevius, D.; Di Luccio, E. In vitro histone lysine methylation by NSD1, NSD2/MMSET/WHSC1 and NSD3/WHSC1L. BMC Struct. Biol. 2014, 14, 1-13. [CrossRef]

26. Sankaran, S.M.; Wilkinson, A.W.; Elias, J.E.; Gozani, O. A PWWP Domain of Histone-Lysine N-Methyltransferase NSD2 Binds to Dimethylated Lys-36 of Histone H3 and Regulates NSD2 Function at Chromatin. J. Biol. Chem. 2016, 291, 8465-8474. [CrossRef] [PubMed]

27. Martinez-Garcia, E.; Popovic, R.; Min, D.-J.; Sweet, S.M.M.; Thomas, P.M.; Zamdborg, L.; Heffner, A.; Will, C.; Lamy, L.; Staudt, L.M.; et al. The MMSET histone methyl transferase switches global histone methylation and alters gene expression in $\mathrm{t}(4 ; 14)$ multiple myeloma cells. Blood 2011, 117, 211-220. [CrossRef] [PubMed]

28. Huang, Z.; Wu, H.P.; Chuai, S.; Xu, F.N.; Yan, F.; Englund, N.; Wang, Z.F.; Zhang, H.L.; Fang, M.; Wang, Y.Z.; et al. NSD2 Is Recruited through Its PHD Domain to Oncogenic Gene Loci to Drive Multiple Myeloma. Cancer Res. 2013, 73, 6277-6288. [CrossRef]

29. Sims, R.J.; Reinberg, D. Histone H3 Lys 4 methylation: Caught in a bind? Genes Dev. 2006, 20, 2779-2786. [CrossRef]

30. Li, Y.L.; Chen, X.; Lu, C. The interplay between DNA and histone methylation: Molecular mechanisms and disease implications. EMBO Rep. 2021, 22, e51803. [CrossRef] [PubMed]

31. Lienert, F.; Mohn, F.; Tiwari, V.K.; Baubec, T.; Roloff, T.C.; Gaidatzis, D.; Stadler, M.B.; Schubeler, D. Genomic Prevalence of Heterochromatic H3K9me2 and Transcription Do Not Discriminate Pluripotent from Terminally Differentiated Cells. PLoS Genet. 2011, 7, e1002090. [CrossRef]

32. Kang, H.B.; Choi, Y.; Lee, J.M.; Choi, K.C.; Kim, H.C.; Yoo, J.Y.; Lee, Y.H.; Yoon, H.G. The histone methyltransferase, NSD2, enhances androgen receptor-mediated transcription. FEBS Lett. 2009, 583, 1880-1886. [CrossRef] [PubMed]

33. Zhou, X.; Edmonson, M.N.; Wilkinson, M.R.; Patel, A.; Wu, G.; Liu, Y.; Li, Y.J.; Zhang, Z.J.; Rusch, M.C.; Parker, M.; et al. Exploring genomic alteration in pediatric cancer using ProteinPaint. Nat. Genet. 2016, 48, 4-6. [CrossRef]

34. Morrison, M.J.; Boriack-Sjodin, P.A.; Swinger, K.K.; Wigle, T.J.; Sadalge, D.; Kuntz, K.W.; Scott, M.P.; Janzen, W.P.; Chesworth, R.; Duncan, K.W.; et al. Identification of a peptide inhibitor for the histone methyltransferase WHSC1. PLoS ONE 2018, 13, e0197082. [CrossRef] [PubMed]

35. Li, W.; Tian, W.; Yuan, G.; Deng, P.; Sengupta, D.; Cheng, Z.; Cao, Y.; Ren, J.; Qin, Y.; Zhou, Y.; et al. Molecular basis of nucleosomal H3K36 methylation by NSD methyltransferases. Nature 2021, 590, 498-503. [CrossRef] 
36. Qiao, Q.; Li, Y.; Chen, Z.; Wang, M.Z.; Reinberg, D.; Xu, R.-M. The Structure of NSD1 Reveals an Autoregulatory Mechanism Underlying Histone H3K36 Methylation. J. Biol. Chem. 2011, 286, 8361-8368. [CrossRef]

37. Böttcher, J.; Dilworth, D.; Reiser, U.; Neumüller, R.A.; Schleicher, M.; Petronczki, M.; Zeeb, M.; Mischerikow, N.; Allali-Hassani, A.; Szewczyk, M.M.; et al. Fragment-based discovery of a chemical probe for the PWWP1 domain of NSD3. Nat. Chem. Biol. 2019, 15, 822-829. [CrossRef]

38. Qin, S.; Min, J.R. Structure and function of the nucleosome-binding PWWP domain. Trends Biochem. Sci. 2014, 39, 536-547. [CrossRef]

39. Vezzoli, A.; Bonadies, N.; Allen, M.D.; Freund, S.M.V.; Santiveri, C.M.; Kvinlaug, B.T.; Huntly, B.J.P.; Gottgens, B.; Bycroft, M. Molecular basis of histone H3K36me3 recognition by the PWWP domain of Brpf1. Nat. Struct. Mol. Biol. 2010, 17, 617-619. [CrossRef] [PubMed]

40. McDaniel, S.L.; Strahl, B.D. Shaping the cellular landscape with Set2/SETD2 methylation. Cell. Mol. Life Sci. 2017, 74, 3317-3334. [CrossRef]

41. Kim, S.M.; Kee, H.J.; Eom, G.H.; Choe, N.W.; Kim, J.Y.; Kim, Y.S.; Kim, S.K.; Kook, H.; Kook, H.; Seo, S.B. Characterization of a novel WHSC1-associated SET domain protein with H3K4 and H3K27 methyltransferase activity. Biochem. Biophys. Res. Commun. 2006, 345, 318-323. [CrossRef]

42. Li, Y.; Trojer, P.; Xu, C.F.; Cheung, P.; Kuo, A.; Drury, W.J.; Qiao, Q.; Neubert, T.A.; Xu, R.M.; Gozani, O.; et al. The Target of the NSD Family of Histone Lysine Methyltransferases Depends on the Nature of the Substrate. J. Biol. Chem. 2009, 284, 34283-34295. [CrossRef]

43. Yuan, G.; Ma, B.; Yuan, W.; Zhang, Z.Q.; Chen, P.; Ding, X.J.; Feng, L.; Shen, X.H.; Chen, S.; Li, G.H.; et al. Histone H2A Ubiquitination Inhibits the Enzymatic Activity of H3 Lysine 36 Methyltransferases. J. Biol. Chem. 2013, 288, 30832-30842. [CrossRef]

44. Yuan, W.; Xu, M.; Huang, C.; Liu, N.; Chen, S.; Zhu, B. H3K36 Methylation Antagonizes PRC2-mediated H3K27 Methylation. J. Biol. Chem. 2011, 286, 7983-7989. [CrossRef]

45. Streubel, G.; Watson, A.; Jammula, S.G.; Scelfo, A.; Fitzpatrick, D.J.; Oliviero, G.; McCole, R.; Conway, E.; Glancy, E.; Negri, G.L.; et al. The H3K36me2 Methyltransferase Nsd1 Demarcates PRC2-Mediated H3K27me2 and H3K27me3 Domains in Embryonic Stem Cells. Mol. Cell 2018, 70, 371-379.e5. [CrossRef]

46. Goldman, M.J.; Craft, B.; Hastie, M.; Repecka, K.; McDade, F.; Kamath, A.; Banerjee, A.; Luo, Y.H.; Rogers, D.; Brooks, A.N.; et al. Visualizing and interpreting cancer genomics data via the Xena platform. Nat. Biotechnol. 2020, 38, 675-678. [CrossRef] [PubMed]

47. Rahman, S.; Sowa, M.E.; Ottinger, M.; Smith, J.A.; Shi, Y.; Harper, J.W.; Howley, P.M. The Brd4 Extraterminal Domain Confers Transcription Activation Independent of pTEFb by Recruiting Multiple Proteins, Including NSD3. Mol. Cell. Biol. 2011, 31, 2641-2652. [CrossRef]

48. Shen, C.; Ipsaro, J.J.; Shi, J.; Milazzo, J.P.; Wang, E.; Roe, J.S.; Suzuki, Y.; Pappin, D.J.; Joshua-Tor, L.; Vakoc, C.R. NSD3-Short Is an Adaptor Protein that Couples BRD4 to the CHD8 Chromatin Remodeler. Mol. Cell 2015, 60, 847-859. [CrossRef]

49. Zhang, Q.; Zeng, L.; Shen, C.; Ju, Y.; Konuma, T.; Zhao, C.; Vakoc, C.R.; Zhou, M.M. Structural Mechanism of Transcriptional Regulator NSD3 Recognition by the ET Domain of BRD4. Structure 2016, 24, 1201-1208. [CrossRef]

50. Spriano, F.; Stathis, A.; Bertoni, F. Targeting BET bromodomain proteins in cancer: The example of lymphomas. Pharmacol. Ther. 2020, 215, 107631. [CrossRef]

51. Zuber, J.; Shi, J.W.; Wang, E.; Rappaport, A.R.; Herrmann, H.; Sison, E.A.; Magoon, D.; Qi, J.; Blatt, K.; Wunderlich, M.; et al. RNAi screen identifies Brd4 as a therapeutic target in acute myeloid leukaemia. Nature 2011, 478, 524-528. [CrossRef] [PubMed]

52. Dawson, M.A.; Prinjha, R.; Dittman, A.; Giotopoulos, G.; Bantscheff, M.; Chan, W.-I.; Robson, S.; Chung, C.-W.; Hopf, C.; Savitski, M.; et al. Inhibition of BET Recruitment to Chromatin As An Effective Treatment for MLL-Fusion Leukaemia. Blood 2011, 118, 55. [CrossRef]

53. Xu, Y.L.; Vakoc, C.R. Targeting Cancer Cells with BET Bromodomain Inhibitors. Cold Spring Harb. Perspect. Med. 2017, 7, a026674. [CrossRef] [PubMed]

54. Kim, S.M.; Kee, H.J.; Choe, N.; Kim, J.Y.; Kook, H.; Kook, H.; Seo, S.B. The histone methyltransferase activity of WHISTLE is important for the induction of apoptosis and HDAC1-mediated transcriptional repression. Exp. Cell Res. 2007, 313, 975-983. [CrossRef]

55. Bannister, A.J.; Schneider, R.; Myers, F.A.; Thorne, A.W.; Crane-Robinson, C.; Kouzarides, T. Spatial Distribution of Di- and Tri-methyl Lysine 36 of Histone H3 at Active Genes. J. Biol. Chem. 2005, 280, 17732-17736. [CrossRef] [PubMed]

56. Zhou, M.S.; Deng, L.W.; Lacoste, V.; Park, H.U.; Pumfery, A.; Kashanchi, F.; Brady, J.N.; Kumar, A. Coordination of Transcription Factor Phosphorylation and Histone Methylation by the P-TEFb Kinase during Human Immunodeficiency Virus Type 1 Transcription. J. Virol. 2004, 78, 13522-13533. [CrossRef]

57. Popovic, R.; Martine-Garcia, E.; Giannopoulou, E.G.; Zhang, Q.W.; Zhang, Q.Y.; Ezponda, T.; Shah, M.Y.; Zheng, Y.P.; Will, C.M.; Small, E.C.; et al. Histone Methyltransferase MMSET/NSD2 Alters EZH2 Binding and Reprograms the Myeloma Epigenome through Global and Focal Changes in H3K36 and H3K27 Methylation. PLoS Genet. 2014, 10, e1004566. [CrossRef]

58. Weinberg, D.N.; Papillon-Cavanagh, S.; Chen, H.F.; Yue, Y.; Chen, X.; Rajagopalan, K.N.; Horth, C.; McGuire, J.T.; Xu, X.J.; Nikbakht, H.; et al. The histone mark H3K36me2 recruits DNMT3A and shapes the intergenic DNA methylation landscape. Nature 2019, 573, 281-286. [CrossRef] 
59. Piunti, A.; Shilatifard, A. The roles of Polycomb repressive complexes in mammalian development and cancer. Nat. Rev. Mol. Cell Biol. 2021, 22, 326-345. [CrossRef]

60. Yuan, S.; Natesan, R.; Sanchez-Rivera, F.J.; Li, J.Y.; Bhanu, N.V.; Yamazoe, T.; Lin, J.H.; Merrell, A.J.; Sela, Y.; Thomas, S.K.; et al. Global Regulation of the Histone Mark H3K36me2 Underlies Epithelial Plasticity and Metastatic Progression. Cancer Discov. 2020, 10, 854-871. [CrossRef]

61. Dhayalan, A.; Rajavelu, A.; Rathert, P.; Tamas, R.; Jurkowska, R.Z.; Ragozin, S.; Jeltsch, A. The Dnmt3a PWWP Domain Reads Histone 3 Lysine 36 Trimethylation and Guides DNA Methylation. J. Biol. Chem. 2010, 285, 26114-26120. [CrossRef] [PubMed]

62. Bock, I.; Dhayalan, A.; Kudithipudi, S.; Brandt, O.; Rathert, P.; Jeltsch, A. Detailed specificity analysis of antibodies binding to modified histone tails with peptide arrays. Epigenetics 2011, 6, 256-263. [CrossRef] [PubMed]

63. Carlson, S.M.; Gozani, O. Nonhistone Lysine Methylation in the Regulation of Cancer Pathways. Cold Spring Harb. Perspect. Med. 2016, 6, a026435. [CrossRef]

64. Saloura, V.; Vougiouklakis, T.; Zewde, M.; Deng, X.; Kiyotani, K.; Park, J.-H.; Matsuo, Y.; Lingen, M.; Suzuki, T.; Dohmae, N.; et al. WHSC1L1-mediated EGFR mono-methylation enhances the cytoplasmic and nuclear oncogenic activity of EGFR in head and neck cancer. Sci. Rep. 2017, 7, 40664. [CrossRef] [PubMed]

65. Lu, T.; Jackson, M.W.; Wang, B.L.; Yang, M.J.; Chance, M.R.; Miyagi, M.; Gudkov, A.V.; Stark, G.R. Regulation of NF-kappa B by NSD1/FBXL11-dependent reversible lysine methylation of p65. Proc. Natl. Acad. Sci. USA 2010, 107, 46-51. [CrossRef] [PubMed]

66. Kudithipudi, S.; Lungu, C.; Rathert, P.; Happel, N.; Jeltsch, A. Substrate Specificity Analysis and Novel Substrates of the Protein Lysine Methyltransferase NSD1. Chem. Biol. 2014, 21, 226-237. [CrossRef]

67. Voutsadakis, I.A. Amplification of 8p11.23 in cancers and the role of amplicon genes. Life Sci. 2021, 264, 118729. [CrossRef] [PubMed]

68. Han, X.; Piao, L.; Zhuang, Q.; Yuan, X.; Liu, Z.; He, X. The role of histone lysine methyltransferase NSD3 in cancer. OncoTargets Ther. 2018, 11, 3847-3852. [CrossRef]

69. Taketani, T.; Taki, T.; Nakamura, H.; Taniwaki, M.; Masuda, J.; Hayashi, Y. NUP98-NSD3 fusion gene in radiation-associated myelodysplastic syndrome with $\mathrm{t}(8 ; 11)(\mathrm{p} 11 ; \mathrm{p} 15)$ and expression pattern of NSD family genes. Cancer Genet. Cytogenet. 2009, 190, 108-112. [CrossRef]

70. Rosati, R.; La Starza, R.; Veronese, A.; Aventin, A.; Schwienbacher, C.; Vallespi, T.; Negrini, M.; Martelli, M.F.; Mecucci, C. NUP98 is fused to the NSD3 gene in acute myeloid leukemia associated with $t(8 ; 11)(p 11.2 ; p 15)$. Blood 2002, 99, 3857-3860. [CrossRef]

71. Wang, G.G.; Cai, L.; Pasillas, M.P.; Kamps, M.P. NUP98-NSD1 links H3K36 methylation to Hox-A gene activation and leukaemogenesis. Nat. Cell Biol. 2007, 9, 804-812. [CrossRef] [PubMed]

72. Khan, J.; Whaley, R.; Cheng, L. Primary Pulmonary NUT Carcinoma with NSD3-NUTM1 Fusion. Am. J. Clin. Pathol. 2020, 154, S83-S84. [CrossRef]

73. Suzuki, S.; Kurabe, N.; Ohnishi, I.; Yasuda, K.; Aoshima, Y.; Naito, M.; Tanioka, F.; Sugimura, H. NSD3-NUT-expressing midline carcinoma of the lung: First characterization of primary cancer tissue. Pathol. Res. Pract. 2015, 211, 404-408. [CrossRef] [PubMed]

74. Kuroda, S.; Suzuki, S.; Kurita, A.; Muraki, M.; Aoshima, Y.; Tanioka, F.; Sugimura, H. Cytological Features of a Variant NUT Midline Carcinoma of the Lung Harboring theNSD3-NUTFusion Gene: A Case Report and Literature Review. Case Rep. Pathol. 2015, 2015, 1-5. [CrossRef] [PubMed]

75. French, C.A.; Rahman, S.; Walsh, E.M.; Kuhnle, S.; Grayson, A.R.; Lemieux, M.E.; Grunfeld, N.; Rubin, B.P.; Antonescu, C.R.; Zhang, S.L.; et al. NSD3-NUT Fusion Oncoprotein in NUT Midline Carcinoma: Implications for a Novel Oncogenic Mechanism. Cancer Discov. 2014, 4, 928-941. [CrossRef]

76. Rathert, P.; Roth, M.; Neumann, T.; Muerdter, F.; Roe, J.-S.; Muhar, M.; Deswal, S.; Cerny-Reiterer, S.; Peter, B.; Jude, J.; et al. Transcriptional plasticity promotes primary and acquired resistance to BET inhibition. Nature 2015, 525, 543-547. [CrossRef] [PubMed]

77. Mahmood, S.F.; Gruel, N.; Nicolle, R.; Chapeaublanc, E.; Delattre, O.; Radvanyi, F.; Bernard-Pierrot, I. PPAPDC1B and WHSC1L1 Are Common Drivers of the 8p11-12 Amplicon, Not Only in Breast Tumors But Also in Pancreatic Adenocarcinomas and Lung Tumors. Am. J. Pathol. 2013, 183, 1634-1644. [CrossRef]

78. Kang, D.; Cho, H.S.; Toyokawa, G.; Kogure, M.; Yamane, Y.; Iwai, Y.; Hayami, S.; Tsunoda, T.; Field, H.I.; Matsuda, K.; et al. The histone methyltransferase Wolf-Hirschhorn syndrome candidate 1-like 1 (WHSC1L1) is involved in human carcinogenesis. Genes Chromosomes Cancer 2013, 52, 126-139. [CrossRef]

79. Yuan, G.; Flores, N.M.; Hausmann, S.; Lofgren, S.M.; Kharchenko, V.; Angulo-Ibanez, M.; Sengupta, D.; Lu, X.; Czaban, I.; Azhibek, D.; et al. Elevated NSD3 histone methylation activity drives squamous cell lung cancer. Nature 2021, 590, 504-508. [CrossRef]

80. Irish, J.C.; Mills, J.N.; Turner-Ivey, B.; Wilson, R.C.; Guest, S.T.; Rutkovsky, A.; Dombkowski, A.; Kappler, C.S.; Hardiman, G.; Ethier, S.P. Amplification of WHSC1L1 regulates expression and estrogen-independent activation of ER $\alpha$ in SUM-44 breast cancer cells and is associated with ER $\alpha$ over-expression in breast cancer. Mol. Oncol. 2016, 10, 850-865. [CrossRef]

81. Rutkovsky, A.C.; Turner-Ivey, B.; Smith, E.L.; Spruill, L.S.; Mills, J.N.; Ethier, S.P. Development of mammary hyperplasia, dysplasia, and invasive ductal carcinoma in transgenic mice expressing the 8p11 amplicon oncogene NSD3 (WHSC1L1). Cancer Res. 2017, 77, 1835. [CrossRef]

82. Liu, Z.; Piao, L.; Zhuang, M.; Qiu, X.; Xu, X.; Zhang, D.; Liu, M.; Ren, D. Silencing of histone methyltransferase NSD3 reduces cell viability in osteosarcoma with induction of apoptosis. Oncol. Rep. 2017, 38, 2796-2802. [CrossRef] [PubMed] 
83. Yi, L.; Yi, L.; Liu, Q.; Li, C. Downregulation of NSD3 (WHSC1L1) inhibits cell proliferation and migration via ERK1/2 deactivation and decreasing CAPG expression in colorectal cancer cells. OncoTargets Ther. 2019, 12, 3933-3943. [CrossRef]

84. Brumbaugh, J.; Kim, I.S.; Ji, F.; Huebner, A.J.; Di Stefano, B.; Schwarz, B.A.; Charlton, J.; Coffey, A.; Choi, J.; Walsh, R.M.; et al. Inducible histone K-to-M mutations are dynamic tools to probe the physiological role of site-specific histone methylation in vitro and in vivo. Nat. Cell Biol. 2019, 21, 1449-1461. [CrossRef]

85. Morgan, M.; Herz, H.M.; Gao, X.; Jackson, J.; Rickels, R.; Swanson, S.K.; Florens, L.; Washburn, M.P.; Eissenberg, J.C.; Shilatifard, A. Histone $\mathrm{H} 3$ lysine-to-methionine mutants as a paradigm to study chromatin signaling. FEBS J. 2015, $282,406$.

86. Fang, D.; Gan, H.Y.; Lee, J.H.; Han, J.; Wang, Z.Q.; Riester, S.M.; Jin, L.; Chen, J.J.; Zhou, H.; Wang, J.L.; et al. The histone H3.3K36M mutation reprograms the epigenome of chondroblastomas. Science 2016, 352, 1344-1348. [CrossRef] [PubMed]

87. Lu, C.; Jain, S.U.; Hoelper, D.; Bechet, D.; Molden, R.C.; Ran, L.L.; Murphy, D.; Venneti, S.; Hameed, M.; Pawel, B.R.; et al. Histone H3K36 mutations promote sarcomagenesis through altered histone methylation landscape. Science 2016, 352, 844-849. [CrossRef] [PubMed]

88. Zhang, Y.; Fang, D. The incorporation loci of H3.3K36M determine its preferential prevalence in chondroblastomas. Cell Death Dis. 2021, 12, 1-16. [CrossRef]

89. Zhang, Y.L.; Shan, C.M.; Wang, J.Y.; Bao, K.; Tong, L.; Jia, S.T. Molecular basis for the role of oncogenic histone mutations in modulating H3K36 methylation. Sci. Rep. 2017, 7, 43906. [CrossRef] 